\title{
The superiority of DEAGP in ranking decision making units over DEA-AHP method: Utilizing relative closeness to ideal decision making units
}

\section{Bahareh vaisi*}

Department of Industrial Engineering, Islamic Azad University, Sanandaj Branch, Sanandaj, Kurdistan, Iran

\begin{tabular}{l}
\hline A R T I C L E I N F O \\
\hline Article history: \\
Received July 2, 2012 \\
Received in Revised form \\
August, 26, 2012 \\
Accepted 18 September 2012 \\
Available online \\
September 212012 \\
\hline Keywords: \\
DEAGP \\
Common set of weights (CSWs) \\
Ideal decision making unit \\
(IDMU) \\
Anti-ideal decision making unit \\
(ADMU) \\
Relative closeness (RC)
\end{tabular}

\section{A B S T R A C T}

Data envelopment analysis (DEA) is one of the most popular techniques for measuring relative efficiencies of various similar units. However, lack of opportunity to compare the decision making units (DMUs) on the same scale in DEA model can make it less practical to classify DMUs. In this paper, we present common weights for DMUs by applying a scientific methodology utilizing goal programming as one of multi criteria decision making (MCDM) techniques, thereby we deal with improving discrimination power for selecting the efficient DMUs. The paper investigates the validity of the ranking technique, an index called the relative closeness (RC) to the ideal DMU (IDMU). Finally, via a previously reported numerical example, the proposed data envelopment analysis-goal programming (DEAGP) model is compared with that obtained by the DEA-AHP.

\section{Introduction}

For years, data envelopment analysis (DEA) has been considered as one of the most well known methods for measuring the relative efficiency of similar units. DEA technique has different advantages such as considering various inputs and outputs. Since the introduction of DEA method by Charnes et al. (1978), there have been thousands of research published by various people. DEA is a mathematical method of performance assessment of decision making units (DMUs). DEA has been successfully implemented to evaluate different kinds of DMUs such as producer units, in recent years. During the past three decades, multiple criteria decision making (MCDM) models have been introduced as a conventional method for analyzing some decision problems in operations research (OR). Dealing with difficulty of DEA model to achieve the required efficiency requires solving DEA method several times. A model for measuring efficiency of DMUs using common set of weights (CSW) by means of goal programming (GP) as an MCDM technique was designed and called data 
envelopment analysis-goal programming (DEA-GP) to reduce the burden of computations. Athanassopoulos (1995) developed an interface between GP and DEA in multilevel planning, which is used in reorganization of the allocation of central funds to local authorities in Greece.

Makui et al. (2008) implemented another multiple objective linear programming (MOLP) approach for generating a common set of weights in the DEA framework, which deals with difficulty and assessing all the DMUs on the same scale. They illustrated the merits of their proposed approach via an example from Kao and Hung (2005). Bal and Örkcü (2007) proposed a multi criteria data envelopment analysis (MCDEA) model to moderate the homogeneity of weights dispersion by using pre-emptive goal programming and compared the results with the classical DEA model via a real data set relative to the socio-economic performances of European countries.

Örkcü and Bal (2011) proposed goal programming approaches for DEA cross efficiency evaluation, which is an alternative method for ranking the decision making units in DEA and it is used in the second stage of the cross evaluation. To achieve an index, which determines an accurate ranking for DMUs, a study by Wang et al. (2006) was accomplished where two virtual DMUs called ideal DMU (IDMU) were introduced and anti-ideal DMU (ADMU) in to the DEA was analyzed. To determine possible relative efficiency from these two perspectives and combining them, a comprehensive index called the relative closeness (RC) to the IDMU was formed. This index was used as the evidence of overall assessment of each DMU, based on an overall ranking of all DMUs.

In this paper, extending the research done by Zarei et al. (2012), DEAGP model was designed and their numerical example was examined one more time. To illustrate the superiority of DEAGP calculations to the DEA-AHP model, the RC index is calculated. The rest of this paper is organized as follows. In Section 2, the structure of DEAGP model is presented and the RC index is explained. In Section 3, both DEAGP and RC index are applied to a real data set from Zarei et al. (2012), research. Finally, in Section 4, we present our results and conclusions.

\section{Methodology}

\subsection{Data Envelopment Analysis-Goal Programming Model}

Makui et al. (2008) proposed a multiple objective linear programming (MOLP) approach for generating a common set of weights (CSWs) in the DEA framework, respectively. To understand a DEAGP model, consider a goal programming, where the decision maker must set some desired goals for each objective. Assume that this goal for objective function $i$ is equal to $g_{i}$, then the multi criteria formulation is given as follows,

$$
\min \sum_{i=1}^{k}\left(d_{i}^{+}+d_{i}^{-}\right)
$$

subject to

$$
Z_{i}-g_{i}=d_{i}^{+}-d_{i}^{-}, h_{i}\left(x_{1}, x_{2}, \ldots \ldots . ., x_{n}\right) \leq \geq b_{i}, d_{i}^{+}, d_{i}^{-} \geq 0 \quad i=1,2, \cdots, k, d_{i} \text { free }
$$

where $g_{i}, \mathrm{i}=1,2, \ldots . ., \mathrm{k}$ are the goals; $\mathrm{z}_{\mathrm{i}}, \mathrm{i}=1, \ldots, \mathrm{k}$ are objectives; $d_{i}^{+}$and $d_{i}^{-}$are deviations from the goals, the first one is over-achievement and the other one is under-achievement of the $\mathrm{i}^{\text {th }}$ goal.

On the other hand, Charnes et al. (1978) formulated the efficiency model for $n$ unit decision makers where there are $m$ inputs and $s$ outputs as a ratio of a weighted sum of outputs to a weighted sum of inputs. The efficiency of unit 'zero' is a fractional linear program as shown in Eq. (2). 
$\max E_{0}=\frac{\sum_{r=1}^{s} u_{r} y_{r 0}}{\sum_{i=1}^{m} v_{i} x_{i 0}}$

subject to

$\frac{\sum_{r=1}^{s} u_{r} y_{r j}}{\sum_{i=1}^{m} v_{i} x_{i j}} \leq 1$

$$
\begin{aligned}
& j=1,2, \ldots \ldots ., n \\
& r=1, \ldots \ldots, s \\
& i=1,2, \ldots . ., m
\end{aligned}
$$$$
u_{r} \geq 0
$$$$
v_{i} \geq 0
$$

where $u_{r}$ and $v_{i}$ are the weight to be applied to the outputs and inputs. Using the proposed efficiency scales, Model (2) is transformed into a common weight multi criteria decision making model, with an improved discrimination power. The proposed efficiency scales are functions of deviation of efficiency. Let $d_{j}$ be the deviation of efficiency of decision making unit $j$ and $E_{j}$ be the deviation of ideal efficiency, i.e., $d_{j}=1-E_{j}$. Then we have,

$\min d_{j 0}$

subject to

$\frac{\sum_{r=1}^{s} u_{r} y_{r j}}{\sum_{i=1}^{m} v_{i} x_{i j}}+d_{j}=1$

$u_{r} \geq \varepsilon$

$j=1,2, \ldots \ldots, n$

$r=1,2, \ldots \ldots . . . S$

The objective functions of models (2) and (3) determine particular DMU. Furthermore, based on models (1) and (3), we have DEAGP model for $n$ decision making unit as follows,

$\min \sum_{j=1}^{n}\left(d_{j}^{-}+d_{j}^{+}\right)$

subject to

$$
\begin{aligned}
& \frac{\sum_{r=1}^{s} u_{r} y_{r j}}{\sum_{i=1}^{m} v_{i} x_{i j}}+d_{j}^{-}-d_{j}^{+}=1 \quad j=1,2, \ldots ., n \\
& u_{r} \geq \varepsilon \quad r=1,2, \ldots ., s \\
& d_{j}^{-} \geq 0 \quad j=1,2, \ldots ., n \\
& d_{j}^{+} \geq 0 \quad j=1,2, \ldots ., n
\end{aligned}
$$

Applying model (4), this one-stage efficiency computation leads to common set of weights amounts and by using the efficiency scores $\sum_{r=1}^{s} u_{r} y_{r j} / \sum_{i=1}^{m} v_{i} x_{i j}$ for each DMU, the relative efficiency of all DMUs will be evaluated.

\subsection{Relative Closeness index to the Ideal Decision Making Unit}

Wang et al. (2006) designed models (5) and (6) by introducing ADMU and IDMU, which provide ${ }^{*}{ }_{j 0}$ and $\varphi^{*}{ }_{j 0}$ for each DMU. Let ${ }^{*}$ IDMU be the optimum efficiency of the IDMU and $\varphi^{*}$ ADMU be the worst efficiency of the ADMU, by using the two virtual DMUs, IDMU and ADMU, relative closeness (RC) index is calculated for each DMU. Models (5) and (6) as follows, 
$\max \theta_{j 0}=\sum_{r=1}^{s} u_{r} y_{r j 0}$

subject to

$\sum_{i=1}^{m} v_{i} X_{i j 0}=1$

$\sum_{r=1}^{s} u_{r} y_{j} \max -\sum_{i=1}^{m} v_{i}\left(\theta *_{I D M U} X_{i} \min \right)=0$

$\sum_{r=1}^{s} u_{r} y_{r j}-\sum_{i=1}^{m} v_{i} x_{i j} \leq 0$

$j=1,2, \cdots, n$

$u_{r} \geq \varepsilon, v_{i} \geq \varepsilon \forall i, r$

Then

$\min \varphi_{j 0}=\sum_{r=1}^{s} u_{r} y_{r j 0}$

subject to $\quad \sum_{i=1}^{m} v_{i} X_{i j 0}=1$

$\sum_{r=1}^{s} u_{r} y_{j} \min -\sum_{i=1}^{m} v_{i}\left(\varphi *_{I D M U} X_{i} \max \right)=0$

$\sum_{r=1}^{s} u_{r} y_{r j}-\sum_{i=1}^{m} v_{i} x_{i j} \geq 0$

$j=1,2, \ldots \ldots, n$

$u_{r} \geq \varepsilon$

$v_{i} \geq \varepsilon \quad \forall i, r$

Finally, the relative closeness (RC) index of $\mathrm{DMU}_{0}$ to IDMU is defined as follows,

$R C_{J 0}=\frac{\varphi *_{j 0}-\varphi *_{A D M U}}{\left(\varphi *_{j 0}-\varphi *_{A D M U}\right)+\left(\theta *_{I D M U}-\theta *_{j 0}\right)}$.

It is clear that the bigger the ${ }_{R C}$ 。 value, the better the efficiency of $\mathrm{DMU}_{0}$.

\section{Numerical example}

In this Section, an example from Zarei et al. (2012) is used. They attempted to classify rivet producer units by applying a composed method on basis of DEA and AHP. Information of output and input variables relating to rivet producer units has been shown in Table 1

Table 1

Output and input variables

\begin{tabular}{cc|cccc}
\hline \multicolumn{2}{c|}{ Ootput } & \multicolumn{4}{c}{ Input } \\
\hline Income & Export & Import & Cost of each rivet & Raw materials number & Rivet code \\
\hline 8100000 & 0 & 60200 & 17.5 & 1000000 & 5006 \\
12750000 & 0 & 94800 & 17.4 & 1500000 & 5008 \\
27300000 & 0 & 195600 & 17.4 & 3000000 & 5009 \\
18120000 & 0 & 134400 & 17.41 & 2000000 & 5010 \\
19360000 & 0 & 142400 & 17.9 & 2000000 & 5012 \\
16440000 & 0 & 125250 & 21.45 & 1500000 & 5014 \\
29600000 & 2500000 & 217500 & 21.5 & 2500000 & 5016 \\
12060000 & 1000000 & 91000 & 21.8 & 1000000 & 5018 \\
\hline
\end{tabular}

In the first stage, by achieving common weights from model (4) and applying them in efficiency score formula, we have the efficiency of each DMU, which can be summarized in Table 2. 
Table 2

The summary of efficiency based on DEAGP model

\begin{tabular}{lcccccccc}
\hline Unit & 1 & 2 & 3 & 4 & 5 & 6 & 7 & 8 \\
\hline efficiency & $9.56 \mathrm{E}-01$ & $9.61 \mathrm{E}-01$ & $1.00 \mathrm{E}+00$ & $9.69 \mathrm{E}-01$ & $9.82 \mathrm{E}-01$ & $9.61 \mathrm{E}-01$ & $1.00 \mathrm{E}+00$ & $9.77 \mathrm{E}-01$ \\
CSWs & $\mathrm{U} 1=0.1027942 \mathrm{E}+08, \mathrm{U} 2=0.1000000 \mathrm{E}-05, \mathrm{~V} 1=0.1292000 \mathrm{E}+10, \mathrm{~V} 2=2.592586$, & $\mathrm{V3}=9304288$
\end{tabular}

In the next stage, by solving models (5) and (6) and applying other required equations from Wang et al. (2012), we could solve RC index using Eq. (7). Table 3 summarizes the details of our computations and finally, determines the RC index value for each DMU.

Table 3

Efficiency ratings and the RC values for each DMU

\begin{tabular}{cccc}
\hline unit & $0_{\mathrm{J} 0}$ & $\Phi_{\mathrm{J} 0}$ & RC \\
\hline 1 & 0.9640393 & 0.9931425 & 0.211888852 \\
2 & 0.963625 & 1 & 0.213467268 \\
3 & 1 & 1.04135 & 0.225410315 \\
4 & 0.9659733 & 1.00921 & 0.215762001 \\
5 & 0.9740956 & 1.023475 & 0.219588742 \\
6 & 0.9404382 & 1 & 0.212007872 \\
7 & 1 & 1.039543 & 0.224995168 \\
8 & 0.9733655 & 1.014385 & 0.217438066 \\
\hline IDMU=3.612957 & & & \\
\hline
\end{tabular}

As we can observe from the results of Tables 2 and Table 3, unit 3 represents the highest ranking followed by unit seven, unit five, unit eight, unit four, unit two, unit six and unit one comes in the last. All the computations were done by Lingo software.

\section{Conclusion}

Data envelopment analysis has been considered as one of the most popular techniques for measuring the relative efficiency of similar decision units. In this paper, we have proposed a new DEA technique, which uses the merits of multiple criteria decision making to improve the efficiency of traditional DEA and reduces the burden of computations. The new proposed model also does not suffer from the lack of capability to compare all similar units on the same scale. A numerical example has been used to demonstrate the implementation and effectiveness of the new method. As a future work, this paper can be extended by considering uncertainty in inputs and outputs in different forms such as fuzzy or using the recent advances of robust optimization and we leave it for interested researchers.

\section{References}

Athanassopoulos, A.D. (1995). Goal programming \& data envelopment analysis (GoDEA) for targetbased multi-level planning: allocating central grants to the Greek local authorities. European Journal of Operational Research, 87(3), 535-550.

Bal, H., \& Örkcü, H.H. (2007). A goal programming approach to weight dispersion in data envelopment analysis. G.U. Journal of Science, 20(4), 117-125.

Charnes, A., Cooper, W.W., \& Rhodes, E. (1978). Measuring the efficiency of decision making units. European Journal of Operational Research, 2, 429-444.

Kao, C., Hung, H.T. (2005). Data envelopment analysis with common weights: the compromise solution approach. Journal of the Operational Research Society, 56, 1196-1203. 
Karsak, E. E., \& Ahiska, S. S. (2005). Practical common weight multi criteria decision making approach with an improved discriminating power for technology selection. International Journal of Production Research, 43(8), 1537-1554.

Lewis, H. F. (2011). Using DEA factor efficiency scores to eliminate subjectivity in goal programming. Advances in Operations Research,Volume 2011, Article ID 259439, 18 pages.

Liu, F.H., Peng, H.H., Chang, H.W. (2006). Ranking DEA efficient units with the most compromising common weights. ORSC \& APORC, 219-234.

Makui, A., Alinezhad, A., Kiani Mavi, R., \& Zohrehbandian, M. (2008). A goal programming method for finding common weights in DEA with an improved discriminating power for efficiency. Journal of Industrial and Systems Engineering, 1(4), 293-303.

Örkcü, H.H., \& Bal, H. (2011). Goal programming approaches for data envelopment analysis cross efficiency evaluation. Appllied Mathematics and Computations, 218 (2), 346-356.

Romero, C. (1991). Hand book of critical issues in goal programming. Pergamon Press.

Talluri, S. (2000). Data envelopment analysis: Models and extensions. Holy S. Lewis, Feature Editor, Pennsylvania State university.

Vaisi, B. (2009). Achieving common set of weights in data envelopment analysis by using multiple criteria decision making. Proceeding of the 2th International conference of Iranian Operations Research Society, Babolsar University.

Wang, Y.M., Luo, Y. (2006). DEA efficiency assessment using ideal and anti-ideal decision making units. Applied Mathematics and Computation, 173, 902-915.

Zarei, A., Mehdiabadi, A., \& Javidnia, M. (2012). Measuring the units efficiency using an integrated DEA-AHP method: A case study of rivet producer. Management Science Letters, 2, 189-196. 